\title{
BMJ Open Asthma and risk of non-respiratory tract infection: a population-based case-control study
}

\author{
Duk Won Bang, ${ }^{1,2}$ Hyeon J Yang, ${ }^{3}$ Eell Ryoo, ${ }^{1,4}$ Majdi N Al-Hasan, ${ }^{5}$ Brian Lahr, ${ }^{6}$ \\ Larry M Baddour, ${ }^{7}$ Barbara P Yawn, ${ }^{8}$ Young J Juhn ${ }^{1,9}$
}

To cite: Bang DW, Yang $\mathrm{HJ}$, Ryoo E, et al. Asthma and risk of non-respiratory tract infection: a populationbased case-control study. BMJ Open 2013;3:e003857. doi:10.1136/bmjopen-2013003857

- Prepublication history for this paper is available online. To view these files please visit the journal online (http://dx.doi.org/10.1136/ bmjopen-2013-003857).

Received 21 August 2013 Revised 28 August 2013 Accepted 29 August 2013

For numbered affiliations see end of article.

\section{Correspondence to} Dr Young J Juhn; juhn.young@mayo.edu

\section{ABSTRACT}

Objectives: Asthmatics have increased risks of airway-related infections. Little is known about whether this is true for non-airway-related serious infections such as Escherichia coli bloodstream infection (BSI). We assessed whether asthma is associated with a risk of developing community-acquired $E$ coli BSI.

Design: The study was designed as a populationbased retrospective case-control study.

Setting: This population-based study was conducted in Olmsted County, Minnesota.

Participants: The study included 259 all eligible community-acquired $E$ coli BSI cases in Olmsted County, MN between 1998 and 2007 and 259 birthdaymatched, gender-matched and residency-matched controls.

Primary and secondary outcome measures: Only community-acquired $E$ coli BSI cases as the primary outcome was included. Asthma status as an exposure was ascertained by predetermined criteria. An adjusted $\mathrm{OR}$ and $95 \% \mathrm{Cl}$ for the association between asthma and risk of community-acquired $E$ coli $\mathrm{BSI}$ was calculated using conditional logistic regression.

Results: Of 259 eligible cases, $179(69 \%)$ were women and mean age was $61 \pm 22$ years. Of the 259 cases $37(14 \%)$ and $16(6 \%)$ of 259 controls had a prior history of asthma (adjusted OR 2.74; $95 \% \mathrm{Cl}$ 1.11 to $6.76 ; p=0.029$ ). The population attributable risk of asthma for community-acquired $E$ coli BSI was $9 \%$. Although not statistically significant, there was a borderline association between having a history of food allergy and increased risk of community-acquired $E$ coli BSI (6\% vs $2 \%$; adjusted OR $3.51 ; 95 \% \mathrm{Cl} 0.94$ to 13.11; $p=0.062$ ).

Conclusions: Based on the findings of the current population-based, case-control investigation, a history of asthma may be associated with risk of communityacquired $E$ coli BSI. The impact of asthma on risk of microbial infections may go beyond airways.

\section{INTRODUCTION}

Asthma is the most common chronic illness in childhood and is a major cause of morbidity in adults, affecting $4-17 \%$ of children and $7.7 \%$ of adults in the USA. ${ }^{1-3}$ About 300

\section{ARTICLE SUMMARY}

Strengths and limitations of this study

- This is the first population-based case-control study using predetermined criteria for asthma status and community-acquired Escherichia coli bloodstream infection. Also, our study setting has the epidemiologic merits of self-contained healthcare environment with comprehensive medical record system for research.

- The study has inherent limitations as a retrospective study. The study participants were predominantly white and were a relatively older population.

million people globally are estimated to be affected by asthma. ${ }^{4}$

Previous studies showed increased risks of microbial infections among individuals with asthma $^{5-10}$ and the population attributable risk for asthma of serious pneumococcal disease was $11-17 \% .{ }^{6}{ }^{10}$ Impaired innate and adaptive immune functions among asthmatics have been suggested for potential underlying mechanisms. ${ }^{11-18}$ These study results are based on microbial infections of the airways. However, little is known about whether asthma status is associated with the risk of non-airway-related bacterial infections such as community-acquired Escherichia coli bloodstream infection (BSI).

Addressing this question should provide an important insight into the nature of the impact of asthma status on susceptibility to microbial infection. Specifically, it will improve our understanding on whether the impact of asthma status on susceptibility to infection goes beyond airways. In investigating this question, community-acquired $E$ coli BSI is suitable because it is not an airway-related infection but genitourinary tract/gastrointestinal origin, $E$ coli is a Gram-negative bacterium with Toll-like receptor (TLR)-4-mediated signal transduction for innate immunity and $E$ coli is 
the most common cause of community-acquired BSI. ${ }^{19} \mathrm{Up}$ to $30 \%$ of individuals who developed community-acquired E coli BSI did not have known risk factors, ${ }^{20}$ suggesting that unrecognised risk factors exist that are associated with the development of community-acquired $E$ coli BSI.

Investigating the relationship between asthma and non-airway-related serious bacterial infections will advance our understanding on the extent to which asthma impacts susceptibility to microbial infections and whether asthma could be an unrecognised risk factor for non-airwayrelated bacterial infections.

We hypothesise that individuals with asthma have an increased risk of community-acquired $E$ coli BSI, as compared to those without asthma. To test this hypothesis, we conducted a population-based retrospective casecontrol study.

\section{METHODS}

This study was designed as a population-based casecontrol study.

\section{Study population and setting}

Olmsted County, Minnesota is an excellent setting to conduct a population-based epidemiological study such as this because medical care is virtually self-contained within the community (nearly all Olmsted County residents receive medical care from two medical centres in the community). The population characteristics of Olmsted County residents are similar to those of non-Hispanic white. ${ }^{21}$ If one grants the authorisation for using medical record for research (almost 95\% of Olmsted County residents), each patient is assigned a unique identifier under the auspices of the Rochester Epidemiology Project (REP) ${ }^{22}$ Using REP resources, we previously demonstrated that incidence rates of asthma for this community are similar to other communities. The annual incidence rate of asthma in Rochester was 238 cases/100 000 persons, which is comparable to those in other communities such as Tecumseh, Michigan $(250 / 100000) .{ }^{23}$

\section{Study participants: case ascertainment}

To test our study hypothesis, we utilised a populationbased incidence parent study, which previously identified the community-acquired cases to study antimicrobial resistance trends of $E$ coli BSI in the community. Details of the case ascertainment have been described previously. ${ }^{19}$ Briefly, using the microbiology databases at Mayo Clinic Rochester and Olmsted Medical Center, all eligible children and adults with monomicrobial $E$ coli BSI ( $\mathrm{n}=274)$ among Olmsted County residents from 1 January 1998 to 31 December 2007 (ie, a populationbased all incident cases of $E$ coli BSI) were identified based on the criteria suggested by Friedman et $a l^{24}$ As $E$ coli BSI is required for inpatient parental treatment, community-acquired $E$ coli BSI was defined by the isolation of $E$ coli from blood cultures at the time of hospital admission or within $48 \mathrm{~h}$ after hospital admission for patients who did not fit the criteria for healthcare-associated infection according to the Friedman's criteria. ${ }^{24}$ Medical records of all participants were reviewed by investigators of the previous study (MNA-H) to confirm the diagnosis of communityacquired $E$ coli BSI, assess clinical features and determine the eligibility. Only community-acquired $E$ coli BSI was included because nosocomial and healthcare-associated $E$ coli BSI are unsuitable to address the aim of the present study (clinically, they are a high-risk population for $E$ coli BSI and not representative of the study population). The index date of BSI was defined as the date when blood cultures that eventually grew $E$ coli were obtained. Exclusion criteria for cases (and controls) included: (1) polymicrobial BSI caused by more than one microorganism, (2) blood cultures acquired at autopsy, (3) nosocomial and healthcare-associated E coli BSI, (4) non-Olmsted County residency at the time of index date of BSI, (5) no research authorisation for using medical record for research and (6) health conditions making ascertainment of asthma difficult listed in box 1 .

\section{Selection of control participants}

Control participants were randomly selected with 1:1 matching from Olmsted County residents who had not had a history of $E$ coli BSI at the end of the study period. Briefly, a list of potential control participants who had received medical care from either Mayo Clinic or Olmsted Medical Center and who met the matching criteria was generated and randomly selected from the REP database for the present study. The matching criteria included: (1) gender, (2) birth date (within 6 months for those $<18$ years of age and within 1 year for those $>18$ years of age), (3) the same clinic registration year as matched case (within 1 year) and (4) closest clinic visit to index date of matched case within 1 year. The index date for control participants was defined as the closest (within 1 year) clinic visit date to index date of BSI for their corresponding matched case. Based on the number of cases and controls enroled in this present study (259 pair), assuming $8 \%$ of asthma prevalence among controls, this present study had $80 \%$ power to detect an effect size of 2.27 of OR (16.5\% of asthma in cases). This effect size was smaller than the reported effect sizes for the association between asthma and risk of microbial infection (OR 2.4-6.7) suggesting adequate statistical power to address the study aim. ${ }^{6} 10$

\section{Exposure ascertainment (asthma status)}

For determining asthma status of all cases and controls, we conducted comprehensive medical record reviews to apply predetermined criteria for asthma as performed in our previous work..$^{5}{ }^{6}$ The criteria are delineated in box 1 . These criteria have been extensively used in research for asthma epidemiology and were found to have high reliability. ${ }^{25-30}$ We included definite as well as probable asthma according to the criteria prior to the index date of BSI cases because most probable asthmatics 


\section{Box 1 Definition of asthma}

Patients were considered to have definite asthma if a physician had made a diagnosis of asthma with the first two conditions and/or if each of the following three conditions were present, and they were considered to have probable asthma if only the first two conditions were present:

1. History of cough with wheezing, and/or dyspnoea, or history of cough and/or dyspnoea plus wheezing on examination

2. Substantial variability in symptoms from time to time or periods of weeks or more when symptoms were absent, and

3. Two or more of the following:

- Sleep disturbance by nocturnal cough and wheeze

- Non-smoker (14 years or older)

- Nasal polyps

- Blood eosinophilia higher than 300/ $\mu \mathrm{L}$

- Positive wheal and flare skin tests or elevated serum IgE

- History of hay fever or infantile eczema or cough, dyspnoea and wheezing regularly on exposure to an antigen

- Pulmonary function tests showing one $\mathrm{FEV}_{1}$ or FVC less than $70 \%$ predicted and another with at least $20 \%$ improvement to an $\mathrm{FEV}_{1}$ of higher $70 \%$ predicted or methacholine challenge test showing $20 \%$ or greater decrease in $\mathrm{FEV}_{1}$

- Favorable clinical response to bronchodilator (eg, documented improvement of respiratory symptoms or $\mathrm{FEV}_{1}$ in spirometry after bronchodilator therapy)

Patients were excluded from the study if any of these conditions were present:

- Tracheobronchial foreign body at or about the incidence date

- Hypogammaglobulinaemia ( $\mathrm{gG}$ less than $2.0 \mathrm{mg} / \mathrm{mL}$ ) or other immunodeficiency disorder

- Wheezing occurring only in response to anaesthesia or medications

- Bullous emphysema or pulmonary fibrosis on chest radiograph

PiZZ $\alpha_{1}$-antitrypsin

- Cystic fibrosis

- Other major chest disease such as juvenile kyphoscoliosis or bronchiectasis FVC forced vital capacity; FEV $_{1}$, forced expiratory volume in $1 \mathrm{~s}$

- Pulmonary function tests that showed $\mathrm{FEV}_{1}$ to be consistently below $50 \%$ predicted or diminished diffusion capacity

become definite over time. ${ }^{6} 31$ The incidence dates (the first date when one met the criteria for asthma) for all patients with asthma were determined; thus, we were able to discern the temporal relationship between asthma status (exposure) and $E$ coli BSI (outcome). The risk of $E$ coli BSI was assessed in relation to the current asthma status $^{32}$ : remission (no asthma symptoms, no asthma-related visits or no asthma medications for at least 3 years prior to index date); active or current asthma (presence of clinical symptoms, asthma-related visits or asthma medications within 1 year prior to index date) and inactive (not current) asthma (presence of asthma symptoms, asthma-related visits or asthma medications within 1-3 years prior to index date).

\section{Other variables}

Pertinent covariates and confounders were collected from medical records: sociodemographic variables (age, gender, ethnicity and educational status), asthma medications including inhaled and systemic corticosteroids, family history of asthma, atopic status based on sensitisation against aeroallergens and food allergens, smoking status (either active or passive exposure to tobacco smoke), vaccination status and comorbid conditions at the time of index date as listed in table 1 . The period of data collection was from 1 October 2011 to 30 May 2012.

\section{Statistical analysis}

Formal comparison of asthma and other suspected risk factors between matched cases and controls was performed using conditional logistic regression, with community-acquired $E$ coli BSI as the target of prediction. All factors were analysed for a univariate association with BSI and any variables meeting the Greenland entry criteria $(p<0.2)$ were carried forward into a final multivariable model. ${ }^{33}$ ORs from univariate (unadjusted) and multivariable (adjusted) models are reported to express the magnitude of association in terms of the likelihood of being a case. We calculated the population attributable risk percentage (PAR\%) of asthma for community-acquired $E$ coli BSI using the formula established by Miettinen. ${ }^{34}$ Statistical significance was tested at a two-sided $\alpha$ error of 0.05 . All analyses were carried out with the statistical software package SAS, V.9.2 (SAS Institute, Cary, North Carolina, USA).

\section{RESULTS}

\section{Study subjects}

Of the 274 patients who were identified in the original study, 259 were eligible for the present study. Fifteen patients were excluded: five for consistent $\mathrm{FEV}_{1}<50 \%$, two for restrictive lung disease, two for significant kyphoscoliosis, two for bronchiectasis, one for cystic fibrosis, one for pulmonary fibrosis and two due to non-Olmsted County residency. Of the eligible 259 cases, $179(69 \%)$ were women, $249(96 \%)$ were 18 years of age or older (age mean \pm SD, 61 \pm 22 years) and 222 $(86 \%)$ were Caucasian. The characteristics of the cases and their matched controls, and the individual associations with community-acquired $E$ coli $\mathrm{BSI}$, are summarised in table 1 . There were only 10 asthmatics on moderate-dose or high-dose inhaled corticosteroid (ICS) and two asthmatics on systemic corticosteroid at the time of the index date. Comparing participants with asthma versus those without, there was no significant difference in the proportions, who had received influenza vaccine ( $40 \%$ vs $40 \%, \mathrm{p}=0.99$ ) or 23 -valent pneumococcal polysaccharide vaccine (PPV23; $49 \%$ vs $44 \%, \mathrm{p}=0.49$ ) within 1 year prior to index date.

\section{Association between asthma and risk of community-acquired $E$ coli BSI}

Of the 259 cases, $37(14 \%)$ had a history of asthma prior to the index date of community-acquired $E$ coli BSI, compared with 16 of $259 \quad(6 \%)$ controls 
Table 1 Sociodemographic and clinical characteristics of patients with Escherichia coli blood stream infection and their matched control participants

\begin{tabular}{|c|c|c|c|c|}
\hline Characteristics & Case $(n=259)$ & Control $(n=259)$ & Unadjusted OR* $(95 \% \mathrm{Cl})$ & p Value \\
\hline Age (years) & $61 \pm 22$ & $61 \pm 22$ & $1.14(0.78$ to 1.67$)$ & 0.497 \\
\hline Female gender & $179(69 \%)$ & $179(69 \%)$ & - & \\
\hline Ethnicity & & & & $<0.001$ \\
\hline Caucasian (non-Hispanic) & $222(86 \%)$ & $245(95 \%)$ & Referent & \\
\hline Other & $37(14 \%)$ & $14(5 \%)$ & 4.83 (2.01 to 11.64$)$ & \\
\hline Education status & & & & 0.004 \\
\hline Some high school or less & $45(17 \%)$ & $21(8 \%)$ & Referent & \\
\hline High school graduate & $95(37 \%)$ & $87(34 \%)$ & $0.50(0.27$ to 0.93$)$ & \\
\hline Some college or more & $110(42 \%)$ & $143(55 \%)$ & $0.33(0.18$ to 0.62$)$ & \\
\hline Unknown & $9(3 \%)$ & $8(3 \%)$ & - & \\
\hline Influenza vaccination 1 year prior to index date & $95(37 \%)$ & $110(42 \%)$ & $0.75(0.51$ to 1.10$)$ & 0.145 \\
\hline PPV23 prior to index date & $117(45 \%)$ & $114(44 \%)$ & 1.08 (0.69 to 1.68$)$ & 0.736 \\
\hline Food allergy & $16(6 \%)$ & $6(2 \%)$ & 2.67 (1.04 to 6.81$)$ & 0.040 \\
\hline Asthma & $37(14 \%)$ & $16(6 \%)$ & 2.75 (1.42 to 5.32$)$ & 0.003 \\
\hline \multicolumn{5}{|l|}{ High-risk conditions } \\
\hline Alcohol addiction & $17(7 \%)$ & $1(0 \%)$ & $17.00(2.26$ to 127.75$)$ & 0.006 \\
\hline Autoimmune disease $\ddagger$ & $9(3 \%)$ & $3(1 \%)$ & $3.00(0.81$ to 11.08$)$ & 0.099 \\
\hline Chronic obstructive lung disease & $12(5 \%)$ & $9(3 \%)$ & 1.37 (0.55 to 3.42$)$ & 0.493 \\
\hline Chronic renal insufficiency & $30(12 \%)$ & $4(2 \%)$ & 9.67 (2.94 to 31.73$)$ & $<0.001$ \\
\hline Congestive heart failure & $19(7 \%)$ & $2(1 \%)$ & $18.00(2.40$ to 134.84$)$ & 0.005 \\
\hline Coronary artery disease & $52(20 \%)$ & 40 (15\%) & $1.46(0.89$ to 2.41$)$ & 0.136 \\
\hline Dementia & $16(6 \%)$ & $7(3 \%)$ & 3.25 (1.06 to 9.97$)$ & 0.039 \\
\hline Diabetes mellitus & $50(19 \%)$ & $24(9 \%)$ & 2.53 (1.44 to 4.43$)$ & 0.001 \\
\hline History of stroke & $15(6 \%)$ & $10(4 \%)$ & $1.71(0.67$ to 4.35$)$ & 0.257 \\
\hline Immobilisation§ & $10(4 \%)$ & $1(0 \%)$ & 10.00 (1.28 to 78.12$)$ & 0.028 \\
\hline Immunosuppressive therapy & $25(10 \%)$ & $4(2 \%)$ & 8.00 (2.41 to 26.57$)$ & 0.001 \\
\hline Malignancy & $21(8 \%)$ & $12(5 \%)$ & $2.00(0.90$ to 4.45$)$ & 0.090 \\
\hline Recurrent urinary tract infection & $29(11 \%)$ & $2(1 \%)$ & 14.50 (3.46 to 60.77$)$ & $<0.001$ \\
\hline Transplant recipients & $8(3 \%)$ & $0(0 \%)$ & - & \\
\hline Urinary incontinence & $46(18 \%)$ & $20(8 \%)$ & $2.86(1.55$ to 5.25$)$ & 0.001 \\
\hline Other condition? & $14(5 \%)$ & $0(0 \%)$ & - & - \\
\hline Smoke & & & & 0.058 \\
\hline No (including ex-smoker) & 206 (80\%) & $222(86 \%)$ & Referent & \\
\hline Active & $53(20 \%)$ & $37(14 \%)$ & 1.59 (0.98 to 2.58$)$ & \\
\hline \multicolumn{5}{|c|}{$\begin{array}{l}\text { *OR based on matched analysis taking into account gender, birthday, residency and follow-up duration } \\
\text { tComorbidity conditions are not mutually exclusive. } \\
\text { fAutoimmune disease includes systemic lupus erythematosus, rheumatoid arthritis, inflammatory bowel disease and other autoimmune } \\
\text { diseases. } \\
\text { §Immobilisation includes hemi/para/quadri-plegia. } \\
\text { qOther conditions include use of urinary catheter, device, genitourinary procedures (eg, prostate biopsy), and congenital anomaly. } \\
\text { PPV23, 23-valent pneumococcal polysaccharide vaccine. }\end{array}$} \\
\hline
\end{tabular}

(unadjusted OR 2.75; 95\% CI 1.42 to 5.32; $\mathrm{p}=0.003$ ). Of the 37 case participants with asthma, $33(89 \%)$ had definite asthma and $4(11 \%)$ had probable asthma. Of the 16 controls with asthma, $12(75 \%)$ had definite asthma and $4(25 \%)$ had probable asthma. Among all 53 asthmatics, 18 were on ICS therapy at the index date ( 8 on low-dose ICS and 10 on moderate to highdose ICS therapy). The effect of asthma on risk of community-acquired $E$ coli BSI, independent of other risk factors, is summarised in table 2. Participants with a history of asthma by predetermined criteria for asthma in box 1 had a nearly threefold higher risk of developing community-acquired $E$ coli BSI compared to those without asthma, controlling for all potential confounding factors (adjusted OR 2.74; 95\% CI 1.11 to $6.76 ; \mathrm{p}=0.029$ ). The $\mathrm{PAR} \%$ of asthma by predetermined criteria for asthma in box 1 for the risk of E coli BSI was $9 \%$. The p values for testing a significant interaction between asthma and categorised age were as follows: $\mathrm{p}=0.285$ for age cut-off of 65 years (ie, $\geq 65$ vs $<65$ years), $\mathrm{p}=0.958$ for age cut-off of 40 years (ie, $\geq 40$ vs $<40$ years) and $\mathrm{p}=0.417$ for age cut-offs of 40 years and 65 years (ie, $<40,40-65$, vs $>65$ years). As a result, we have no evidence of a differential asthma effect across age strata. Additional characteristics of asthma were also evaluated for an association with risk of community-acquired $E$ coli BSI (see table 3). Adjusted for other factors, active asthma was associated with increased risk of $E$ coli BSI but for asthmatics on ICS therapy compared to non-asthmatics; however, the 
Table 2 A multivariable conditional logistic regression model for the association between asthma and risk of community-acquired Escherichia coli bloodstream infection

\begin{tabular}{|c|c|c|c|c|}
\hline Characteristics & Case $(n=259)$ & Control $(n=259)$ & Adjusted OR* (95\% Cl) & p Value \\
\hline Ethnicity & & & & 0.003 \\
\hline Caucasian (non-Hispanic) & $222(86 \%)$ & $245(95 \%)$ & Referent & \\
\hline Other & $37(14 \%)$ & $14(5 \%)$ & 5.90 (1.85 to 18.84$)$ & \\
\hline Education status & & & & 0.646 \\
\hline Some high school or less & $45(17 \%)$ & $21(8 \%)$ & Referent & \\
\hline High school graduate & $95(37 \%)$ & $87(34 \%)$ & 0.89 (0.37 to 2.14$)$ & \\
\hline Some college or more & $110(42 \%)$ & $143(55 \%)$ & $0.65(0.28$ to 1.50$)$ & \\
\hline Unknown & $9(3 \%)$ & $8(3 \%)$ & - & \\
\hline Influenza vaccination 1 year prior to index date & $95(37 \%)$ & $110(42 \%)$ & $0.58(0.33$ to 1.02$)$ & 0.058 \\
\hline Food allergy & $16(6 \%)$ & $6(2 \%)$ & 3.51 (0.94 to 13.11$)$ & 0.062 \\
\hline Asthma & 37 (14\%) & $16(6 \%)$ & 2.74 (1.11 to 6.76$)$ & 0.029 \\
\hline Active smoking & $53(20 \%)$ & 37 (14\%) & 1.31 (0.69 to 2.47$)$ & 0.412 \\
\hline \multicolumn{5}{|l|}{ High-risk conditions } \\
\hline Alcohol addiction & $17(7 \%)$ & $1(0 \%)$ & 32.31 (1.91 to 546.18$)$ & 0.016 \\
\hline Autoimmune diseases & $9(3 \%)$ & $3(1 \%)$ & $1.79(0.23$ to 13.72$)$ & 0.574 \\
\hline Chronic renal insufficiency & $30(12 \%)$ & $4(2 \%)$ & 4.76 (1.16 to 19.59$)$ & 0.030 \\
\hline Congestive heart failure & $19(7 \%)$ & $2(1 \%)$ & $9.86(0.93$ to 104.59$)$ & 0.058 \\
\hline Coronary artery disease & $52(20 \%)$ & $40(15 \%)$ & $0.81(0.37$ to 1.77$)$ & 0.593 \\
\hline Dementia & $16(6 \%)$ & $7(3 \%)$ & $4.14(0.96$ to 17.96$)$ & 0.057 \\
\hline Diabetes mellitus & $50(19 \%)$ & $24(9 \%)$ & 2.39 (0.97 to 5.87$)$ & 0.057 \\
\hline Immobilisation & $10(4 \%)$ & $1(0 \%)$ & 39.86 (2.30 to 690.42$)$ & 0.011 \\
\hline Immunosuppressive therapy & $25(10 \%)$ & $4(2 \%)$ & 8.51 (1.32 to 54.96$)$ & 0.024 \\
\hline Malignancy & $21(8 \%)$ & $12(5 \%)$ & 2.18 (0.59 to 8.11$)$ & 0.243 \\
\hline Recurrent urinary tract infection & $29(11 \%)$ & $2(1 \%)$ & 13.54 (2.42 to 75.65$)$ & 0.003 \\
\hline Urinary incontinence & $46(18 \%)$ & $20(8 \%)$ & 2.57 (1.05 to 6.26$)$ & 0.038 \\
\hline
\end{tabular}

overall three-level effect was not statistically significant $(\mathrm{p}=0.079)$.

\section{Other variables and $E$ coli BSI}

Several of the high-risk conditions, as well as non-Caucasian ethnicity, were independently associated with increased risk of community-acquired $E$ coli BSI (see tables 1 and 2). A history of food allergy was found in $16(6 \%)$ of 259 cases as compared with $6(2 \%)$ of 259 controls (adjusted OR 3.51; 95\% CI 0.94 to 13.11; $\mathrm{p}=0.062)$. Neither allergic rhinitis $(\mathrm{p}=0.82)$ nor atopic dermatitis $(\mathrm{p}=0.87)$ was found to be significantly associated with community-acquired $E$ coli BSI.

\section{DISCUSSION}

To our knowledge, this is the first population-based, casecontrol study that demonstrated an association between asthma and risk of non-respiratory bacterial infection such as community-acquired $E$ coli BSI. This association was

Table 3 Association of asthma control status and therapy with risk of community-acquired Escherichia coli bloodstream infection

\begin{tabular}{|c|c|c|c|}
\hline Asthma characteristics & Total $(n=518)$ & $\begin{array}{l}\text { Unadjusted OR }(95 \% \mathrm{Cl}) \text {, } \\
\text { p Value }\end{array}$ & $\begin{array}{l}\text { Adjusted } \mathrm{OR}^{\star}(95 \% \mathrm{Cl}) \text {, } \\
\text { p Value }\end{array}$ \\
\hline Inhaled corticosteroid therapy (ICS) & & $p=0.009 \dagger$ & $p=0.079 \dagger$ \\
\hline No asthma & $465(90 \%)$ & Referent & Referent \\
\hline Asthma without ICS & $35(7 \%)$ & 1.90 (0.88 to 4.09$)$ & $1.99(0.67$ to 5.94$)$ \\
\hline Asthma with ICS & $18(3 \%)$ & $7.00(1.59$ to 30.80$)$ & $5.33(0.90$ to 31.66$)$ \\
\hline Asthma status $\ddagger$ & & $p=0.005 t$ & $p=0.067 \dagger$ \\
\hline No asthma & $465(90 \%)$ & Referent & Referent \\
\hline Remission or inactive asthma & $17(3 \%)$ & $1.25(0.45$ to 3.50$)$ & $1.25(0.25$ to 6.30$)$ \\
\hline Active or current asthma & $36(7 \%)$ & 4.37 (1.80 to 10.62$)$ & 3.89 (1.23 to 12.28$)$ \\
\hline
\end{tabular}

*Adjusted variables included all factors reported in the multivariable model (see table 2) except for dichotomous asthma status. tp Value for overall comparison.

$\ddagger$ Active or current asthma was defined as the presence of asthma-related events including asthma symptoms, or use of asthma medications, and outpatient/emergency department/hospitalisation for asthma within 1 year prior to index date of $E$ coli $\mathrm{BSI}$; remission of asthma was defined as the absence of asthma-related events $>3$ years prior to index date; inactive (not current) asthma was defined as the presence of asthma-related events within 1-3 years prior to index date. 
independent of other risk factors including age, gender, follow-up duration, ethnicity, educational level and comorbid conditions (adjusted OR 2.74; 95\% CI 1.11 to6.76; $\mathrm{p}=0.029$ ). Analyses by different age cut-offs showed that the results were not affected by age (eg, younger vs older than 40 years of age). Given either the previously reported non-association (HR $1.29,95 \%$ CI 0.53 to 3.12 ) or a protective effect (HR $0.52,95 \%$ CI 0.36 to 0.76 ) of ICS therapy on risk of pneumonia in asthmatics ${ }^{35}$ and a small number of asthmatics with moderate or high-dose ICS in our study (10 of 53,19\%), we suspect that active or current asthma (or collectively those given ICS therapy) might be related to risk of community-acquired $E$ coli BSI instead of ICS alone. There were only two patients with asthma on systemic corticosteroid therapy at the time of the index date; therefore, exposure to systemic corticosteroid therapy was unlikely to account for the observed association. We believe that susceptibility bias (eg, covariate imbalance at baseline) is unlikely to account for the association found in our study given the full adjustment for potential confounders. One concern could be detection bias stemming from a situation where exposure status (asthma status) systematically affects detection of outcomes. However, given that $E$ coli $\mathrm{BSI}$ is a life-threatening condition, this is unlikely and also there was no significant difference in symptom duration from BSI-related symptom to index date between asthma and non-asthma in cases $(4.7 \pm 5.5$ vs $5.2 \pm 5.5$ days, $\mathrm{p}=0.61)$. Since detection of asthma depends on follow-up duration from registration to index date of community-acquired $E$ coli BSI, we designed our study to ensure that duration was similar between cases and controls. Asthma prevalence in controls in our study was $6 \%$, which is similar to that in adults $(7 \%)$ in the USA (5.5\% for men and $9.7 \%$ for women) ${ }^{36}$ Also, the prevalence of other common chronic conditions such as coronary heart disease in our study $(15 \%)$ was similar to the national average $(7.1 \%$ for adults aged $45-64$ years and $19.8 \%$ for adults aged $\geq 65$ years) suggesting that our control group may reasonably represent a general population of adults in the USA. ${ }^{3}$ There were no significant differences in influenza and PPV23 vaccination rates between cases and controls, which may imply similar access to healthcare services. Also, food allergy approached a statistically significant association with the risk of $E$ coli BSI but other atopic conditions did not. This is probably due to greater misclassification bias of ascertainment of allergic rhinitis and atopic dermatitis by International Classification of Diseases (ICD)-9 code compared to asthma status and food allergy by predetermined criteria in our study. Taken together, our study results suggest that asthma status is independently associated with risk of community-acquired E coli BSI.

There are only a few previous studies, which assessed the incidence of $E$ coli BSI and risk factors associated with its development, including asthma. One study showed a higher risk of community-acquired $E$ coli BSI in asthmatics compared to non-asthmatics among those over 65 years of age $(5.5 \%$ vs $1 \%) \cdot{ }^{37}$ However, another study showed reduced risk of $E$ coli BSI in asthmatics (rate ratio: $0.3 ; 95 \%$ CI 0.2 to 0.4 ) compared to that in the total regional population. ${ }^{38}$ These studies have significant limitations including no a priori hypothesis testing on the relationship between asthma and risk of community-acquired $E$ coli BSI, utilisation of administrative data from healthcare organisations or case reports, ascertainment of $E$ coli BSI cases and asthma based on ICD-9 code, inclusion of only elderly patients aged over 65 years ${ }^{37}$ and no concurrent control group. ${ }^{38}$ Thus, our study is the first population-based case-control study that demonstrated a relationship between asthma and risk of community-acquired $E$ coli BSI. Several studies showed increased risks of microbial infections in asthmatics, ${ }^{5-7} 1011$ but these studies only addressed the relationship between asthma and airway infections.

The mechanisms underlying the apparent association between asthma and risk of community-acquired $E$ coli BSI are unknown. Whether previously reported impaired innate immune factors that may predispose to infections due to viruses ${ }^{13} 3940$ and other bacteria are operative in community-acquired E coli BSI is undefined. Recently, Habibzay et $a l^{11}$ reported impaired innate immunity against pneumococci through impaired TLR-receptor signal transduction by house dust mite allergic sensitisation resulting in reduced neutrophil recruitment and increased risk of pneumococcal infection in the airways. It is worth investigating whether allergic sensitisation can induce similar impairment of innate immunity through TLR-4 for Gram-negative bacteria in genitourinary or gastrointestinal tracts in asthmatics. Also, an adaptive immune response to Gram-negative bacteria might be altered in asthmatics, ${ }^{41}$ which may affect susceptibility to Gram-negative bacterial infection. For example, Koch et al reported impaired type 1 helper $\mathrm{T}$ cell (Th1) response (interleukin-12-induced interferon- $\gamma$ release from T lymphocytes) to endotoxin from Salmonella enteritidis in asthmatics. ${ }^{42}$ Further studies are needed to address our study findings.

The main strengths of our study are a population-based study design and include the epidemiological merits of self-contained healthcare environment with comprehensive medical record system for research. We identified population-based all incident community-acquired $E$ coli BSI cases based on the Friedman criteria. We ascertained asthma status by applying predetermined criteria independent of a physician diagnosis of asthma or ICD-9 code. Also, our study has inherent limitations as a retrospective study. We could not obtain detailed information on certain variables such as atopic sensitisation data or smoking history (eg, duration or the number of cigarettes a day) but we assumed these data to be missing at random (ie, it is subject to non-differential misclassification bias for comparison groups of interest). Although our criteria for asthma was based on medical record review, given the absence of a gold standard for asthma, the retrospective investigation for feasibility (due to infrequent $E$ coli $\mathrm{BSI}$ ) and the extensive use of the criterion in 
previous asthma research, we believe the criterion is unlikely to result in a significant bias affecting interpretation of the results. Our study finding that asthma prevalence among controls was similar to that at the national level should mitigate this concern. Our study participants were predominantly white which might limit generalisability of our results to other ethnic groups. Our study participants were relatively an older population affected by many comorbid conditions, which might confound the study results. Therefore, we adjusted the association between asthma and risk of $E$ coli BSI for each comorbid condition individually in our multivariate model. Since the prevalence of comorbid conditions is related to age, we examined the effect of the interaction between age and asthma. We found that the main results on the association between asthma and risk of $E$ coli BSI did not appear to be significantly affected by various cut-offs of age suggesting the results did not differ by age group (younger vs older group).

In conclusion, asthmatics might be at an increased risk of non-respiratory tract bacterial infections, including community-acquired $E$ coli BSI. The mechanisms responsible for this association are yet to be defined while additional investigations replicate our study findings.

\author{
Author affiliations \\ ${ }^{1}$ Department of Pediatric and Adolescent Medicine, Mayo Clinic, Rochester, \\ Minnesota, USA \\ ${ }^{2}$ Department of Internal Medicine, Soonchunhyang University Hospital, Seoul, \\ South Korea \\ ${ }^{3}$ Department of Pediatrics, Soonchunhyang University Hospital, Seoul, \\ South Korea \\ ${ }^{4}$ Department of Pediatrics, Gil Hospital, Gachon University School of \\ Medicine, Inchon, South Korea \\ ${ }^{5}$ Department of Medicine, University of Kentucky Medical Center, Lexington, \\ Kentucky, USA \\ ${ }^{6}$ Division of Biomedical Statistics and Informatics, Mayo Clinic, Rochester, \\ Minnesota, USA \\ ${ }^{7}$ Department of Medicine, Mayo Clinic, Rochester, Minnesota, USA \\ ${ }^{8}$ Department of Research, Olmsted Medical Center, Rochester, Minnesota, \\ USA \\ ${ }^{9}$ Department of Internal Medicine, Mayo Clinic, Rochester, Minnesota, USA
}

Acknowledgements We thank the staff of the Pediatric Asthma Epidemiology Research Unit for their comments and suggestions. We also thank Elizabeth Krusemark for administrative assistance. This work was supported by the Clinician Scholarly Award from the Mayo foundation and by the Rochester Epidemiology Project (R01-AG34676) from the National Institute on Aging. The sponsor of the study had no role in study design, data collection, data analysis, data interpretation or writing of the report.

Contributors DWB collected data, interpreted the results and drafted the manuscript; HJY participated in the study design, interpreted the results and reviewed the manuscript; ER collected data, interpreted the results and reviewed the manuscript; MNA-H assembled the original dataset for the $E$ coli BSI study, collected the original data, interpreted the results and reviewed the manuscript; LMB and BPY participated in the study design, interpreted the results and reviewed the manuscript; and YJJ participated in the study design, performed data analysis, interpreted the results and drafted the manuscript. DWB, ER and YJJ had full access to data. All authors reviewed and approved the paper.

Funding This work was supported by the Clinician Scholarly Award from the Mayo foundation and a grant from the National Institute of Allergy and Infectious Diseases (R21 Al101277). It was also supported by the Rochester Epidemiology Project (R01-AG34676) from the National Institute on Aging.
Competing interests None.

Ethics approval The study was approved by the Institutional Review Boards of both Mayo Clinic and Olmsted Medical Center.

Provenance and peer review Not commissioned; externally peer reviewed.

Data sharing statement No additional data are available.

Open Access This is an Open Access article distributed in accordance with the Creative Commons Attribution Non Commercial (CC BY-NC 3.0) license, which permits others to distribute, remix, adapt, build upon this work noncommercially, and license their derivative works on different terms, provided the original work is properly cited and the use is non-commercial. See: http:// creativecommons.org/licenses/by-nc/3.0/

\section{REFERENCES}

1. Eder W, Ege MJ, von Mutius E. The asthma epidemic. N Engl J Med 2006;355:2226-35.

2. Barnett SB, TA N. Costs of asthma in the United States: 2002-2007. J Allergy Clin Immunol 2011;127:145-52.

3. The Center for Disease Control and Prevention. Vital signs: asthma prevalence, disease characteristics, and self-management education -United States, 2001-2009. MMWR Morb Mortal Wkly Rep 2011;60:547-52.

4. Bernsen RM, van der Wouden JC, Nagelkerke NJ, et al. Early life circumstances and atopic disorders in childhood. Clin Exp Allergy 2006;36:858-65.

5. Capili CR, Hettinger A, Rigelman-Hedberg N, et al. Increased risk of pertussis in patients with asthma. J Allergy Clin Immunol 2012;129:957-63.

6. Juhn YJ, Kita H, Yawn BP, et al. Increased risk of serious pneumococcal disease in patients with asthma. J Allergy Clin Immunol 2008:122:719-23.

7. Jung JA, Kita H, Yawn BP, et al. Increased risk of serious pneumococcal disease in patients with atopic conditions other than asthma. J Allergy Clin Immunol 2010;125:217-21.

8. Klemets P, Lyytikainen O, Ruutu P, et al. Risk of invasive pneumococcal infections among working age adults with asthma. Thorax 2010;65:698-702.

9. Pilishvili T, Zell ER, Farley MM, et al. Risk factors for invasive pneumococcal disease in children in the era of conjugate vaccine use. Pediatrics 2010;126:e9-17.

10. Talbot TR, Hartert TV, Mitchel E, et al. Asthma as a risk factor for invasive pneumococcal disease. N Engl J Med 2005;352:2082-90.

11. Habibzay M, Saldana Jl, Goulding J, et al. Altered regulation of Toll-like receptor responses impairs antibacterial immunity in the allergic lung. Mucosal Immunol 2012;5:524-34.

12. Jung J, Kita H, Nahm M, et al. Influence of asthma status on serotype specific antibody pneumococcal antibody levels. Postraduate Med 2010;122:116-24.

13. Contoli M, Message SD, Laza-Stanca V, et al. Role of deficient type III interferon-lambda production in asthma exacerbations. Nat Med 2006;12:1023-6.

14. Wark PA, Johnston SL, Bucchieri F, et al. Asthmatic bronchial epithelial cells have a deficient innate immune response to infection with rhinovirus. J Exp Med 2005;201:937-47.

15. Message SD, Laza-Stanca V, Mallia P, et al. Rhinovirus-induced lower respiratory illness is increased in asthma and related to virus load and Th1/2 cytokine and IL-10 production. Proc Natl Acad Sci USA 2008;105:13562-7.

16. Laza-Stanca V, Message SD, Edwards MR, et al. The role of IL-15 deficiency in the pathogenesis of Virus-induced asthma exacerbations. PLoS Pathog 2011;7:e1002114.

17. Plummeridge MJ, Armstrong L, Birchall MA, et al. Reduced production of interleukin 12 by interferon $\gamma$ primed alveolar macrophages from atopic asthmatic subjects. Thorax 2000;55:842-7.

18. Ho C-Y, Wong C-K, Ko FW-S, et al. Apoptosis and b-cell lymphoma-2 of peripheral blood t lymphocytes and soluble fas in patients with allergic asthma*. Chest 2002;122:1751-8.

19. Al-Hasan MN, Lahr BD, Eckel-Passow JE, et al. Antimicrobial resistance trends of Escherichia coli bloodstream isolates: a population-based study, 1998-2007. J Antimicrob Chemother 2009;64:169-74.

20. Cheong Hs Fau-Kang C-I, Kang Ci Fau-Kwon KT, Kwon Kt Fau-Heo ST, et al. Clinical significance of healthcare-associated infections in community-onset Escherichia coli bacteraemia. $J$ Antimicrob Chemother 2007;60:1355-60. 
21. St. Sauver JL, Grossardt BR, Yawn BP, et al. Use of a medical records linkage system to enumerate a dynamic population over time: the Rochester Epidemiology Project. Am J Epidemiol 2011;173:1059-68.

22. Kurland LT, Molgaard CA. The patient record in epidemiology. Sci Am 1981;245:54-63.

23. Broder I, Higgins MW, Mathews KP, et al. Epidemiology of asthma and allergic rhinitis in a total community, Tecumseh, Michigan: III. Second survey of the community. J Allergy Clin Immunol 1974;53:127-38.

24. Friedman ND, Kaye KS, Stout JE, et al. Health care-associated bloodstream infections in adults: a reason to change the accepted definition of community-acquired infections. Ann Intern Med 2002:137:791-7.

25. Yunginger JW, Reed CE, O'Connell EJ, et al. A community-based study of the epidemiology of asthma. Incidence rates, 1964-1983. Am Rev Respir Dis 1992;146:888-94.

26. Silverstein MD, Reed CE, O'Connell EJ, et al. Long-term survival of a cohort of community residents with asthma. $N$ Engl J Med 1994;331:1537-41.

27. Bauer BA, Reed CE, Yunginger JW, et al. Incidence and outcomes of asthma in the elderly. A population-based study in Rochester, Minnesota. Chest 1997;111:303-10.

28. Juhn YJ, Qin R, Urm S, et al. The influence of neighborhood environment on the incidence of childhood asthma: a propensity score approach. J Allergy Clin Immunol 2010;125:838-43.e2.

29. Juhn YJ, Sauver JS, Katusic $S$, et al. The influence of neighborhood environment on the incidence of childhood asthma: a multilevel approach. Soc Sci Med 2005;60:2453-64.

30. Yawn BP, Yunginger JW, Wollan PC, et al. Allergic rhinitis in Rochester, Minnesota residents with asthma: frequency and impact on health care charges. J Allergy Clin Immunol 1999;103 (1 Pt 1):54-9.
31. Yunginger J, Reed CE, O'Connell EJ, et al. A community-based study of the epidemiology of asthma: incidence rates, 1964-1983. Am Rev Respir Dis 1992;146:888-94.

32. Javed $\mathrm{A}$, Yoo $\mathrm{KH}$, Jacobson RM, et al. Characteristics of children with asthma who achieved remission of asthma.J Asthma 2013; 50:472-479.

33. Greenland S. Modeling and variable selection in epidemiologic analysis. Am J Public Health 1989;79:340-9.

34. Miettinen OS. Proportion of disease caused or prevented by a given exposure, trait or intervention. Am J Epidemiol 1974;99:325-32.

35. O'Byrne PM, Pedersen S, Carlsson L-G, et al. Risks of pneumonia in patients with asthma taking inhaled corticosteroids. Am J Respir Crit Care Med 2011;183:589-95.

36. The Center for Disease Control and Prevention. Prevalence of coronary heart disease: United States, 2006-2010. MMWR Morb Mortal Wkly Rep 2011;60:1377-81.

37. Jackson LA, Benson P, Neuzil KM, et al. Burden of communityonset Escherichia coli bacteremia in seniors. $J$ Infect Dis 2005; 191:1523-9.

38. Laupland KB GD, Church DL, Ross T, et al. Incidence, risk factors and outcomes of Escherichia coli blood stream infections in a large Canadian region. Clin Microbiol Infect 2008;14:1041-7.

39. Sykes A, Edwards MR, Macintyre J, et al. Rhinovirus 16-induced IFN-alpha and IFN-beta are deficient in bronchoalveolar lavage cells in asthmatic patients. J Allergy Clin Immunol 129:1506-14 e6.

40. Wang L, Zhao L, Lv J, et al. BLT1-dependent alveolar recruitment of CD4+CD25+ Foxp3+ regulatory T Cells is important for resolution of acute lung injury. Am J Respir Crit Care Med 2012;186:989-98.

41. Robinson DS. Regulatory T cells and asthma. Clin Exp Allergy 2009;39:1314-23

42. Koch A, Knobloch J, Dammhayn C, et al. Effect of bacterial endotoxin LPS on expression of INF-gamma and IL-5 in T-lymphocytes from asthmatics. Clin Immunol 2007;125:194-204. 